"This is the peer reviewed version of the following article: [The journal of gene medicine, 2018, pp. e3017], which has been published in final form at [http://doi.org/10.1002/jgm.3017]. This article may be used for non-commercial purposes in accordance with Wiley Terms and Conditions for Self-Archiving." 


\section{PARTIAL PANCREATIC TRANSDIFFERENTIATION OF PRIMARY HUMAN HEPATOCYTES IN THE LIVERS OF A HUMANISED MOUSE MODEL}

Binhai Ren ${ }^{1,2}$, Que T. La ${ }^{1,2}$, Bronwyn A. O’Brien ${ }^{1,2}$, Najah T. Nassif ${ }^{1,2}$, Yi Tan $^{1}$, Dario Gerace $^{1,2}$, Rosetta Martiniello-Wilks ${ }^{1,2}$, Fraser Torpy ${ }^{1}$, Allison P. Dane ${ }^{3}$, lan E. Alexander ${ }^{3,4}$, Ann M. Simpson ${ }^{1,2}$

${ }^{1}$ School of Life Sciences and ${ }^{2}$ The Centre for Health Technologies, University of Technology Sydney, Sydney, Australia:

${ }^{3}$ The Children's Hospital at Westmead and Children's Medical Research Institute, Westmead, Sydney, Australia

${ }^{4}$ Discipline of Child and Adolescent Health, University of Sydney, Westmead, Sydney, Australia.

Running Title: Pancreatic differentiation of human hepatocytes

Corresponding Author: Prof. Ann M. Simpson

School of Life Sciences

University of Technology Sydney

15 Broadway, Ultimo, NSW, 2007

Australia

Tel: $\quad 61295144097$

Email: Ann.Simpson@uts.edu.au

Keywords: diabetes, liver, gene - expression, gene - therapy, immunohistochemistry, vector - viral. 


\section{Abstract:}

Background: Gene therapy is one treatment that may ultimately cure Type 1 diabetes. We have previously shown that introduction of furin-cleavable human insulin (INS-FUR) to the livers in several animal models of diabetes has resulted in reversal of diabetes and partial pancreatic transdifferentiation of liver cells. This study assessed if streptozotocin (STZ)diabetes could be reversed in FRG mice in which chimeric mouse-human livers can be established, and if pancreatic transdifferentiation occurred in the engrafted human hepatocytes.

Methods: Engraftment of human hepatocytes was verified by measuring human albumin levels. Following delivery of the empty vector or the INS-FUR vector to diabetic FRG mice, mice were monitored for weight and blood glucose levels. Intraperitoneal glucose tolerance tests (IPGTTs) were performed. Expression levels of pancreatic hormones and transcription factors were determined by reverse transcriptase PCR (RT-PCR) and immunohistochemistry.

Results: Diabetes was reversed for a period of 60 days (experimental endpoint) after transduction with INS-FUR. IPGTTs of the insulin-transduced animals were not significantly different from nondiabetic animals. Immunofluorescence microscopy revealed expression of human albumin and insulin in transduced liver samples. Quantitative RT-PCR showed expression of human and mouse endocrine hormones and $\beta$-cell transcription factors, indicating partial pancreatic transdifferentiation of mouse and human hepatocytes. Nonfasting human C-peptide levels were significantly higher than mouse levels, suggesting that transdifferentiated human hepatocytes made a significant contribution to diabetes reversal.

Conclusions: These data show that human hepatocytes can be induced to undergo partial pancreatic transdifferentiation in vivo, indicating that the technology holds promise for treatment of Type 1 diabetes. 


\section{INTRODUCTION}

Type I diabetes (T1D) is caused by the autoimmune destruction of pancreatic beta $(\beta)$-cells ${ }^{1}$. Current treatment requires multiple daily injections of insulin to control blood glucose levels. Gene therapy is one strategy that holds promise to cure the disease. Of the accessible primary cells available, our laboratory, and others, have shown that hepatocytes are suitable target cells for the genetic engineering of artificial $\beta$-cells ${ }^{2-13}$. Most importantly, liver cells express the high capacity glucose transporter, GLUT $2^{14}$, and the high capacity phosphorylation enzyme, glucokinase ${ }^{15}$, which constitute the key elements of the "glucose sensing system" that regulates insulin release from pancreatic $\beta$-cells in response to small extracellular nutrient changes. Studies have also shown that these insulin-secreting liver cells are resistant to the detrimental effects of classical $\beta$-cell cytotoxins and proinflammatory cytokines that play principal roles in the autoimmune process of diabetes ${ }^{10,16-}$ 18. Additionally, no infiltrates of immune cells were found in nonobese diabetic (NOD) mice engineered to express insulin in their livers ${ }^{10,17}$. Thus, liver cells are attractive candidates for the creation of artificial $\beta$-cells to cure diabetes.

In order to obtain high transduction rates in diabetic animal livers using a lentiviral vector, we developed a microsurgical procedure of intervallic infusion in full flow occlusion (FFO), which involves clamping the major veins and arteries to stop blood flow to the liver whilst the vector is injected into the portal circulation. This allowed the vector, containing the insulin gene, to remain isolated within the liver, with resultant high transduction rates $[60 \%$ in streptozotocin (STZ)-diabetic rats ${ }^{9}$ and $42 \%$ in spontaneously-diabetic NOD mice ${ }^{10}$ ]. Using this technique, similar results were seen in a pancreatectomised pig model ${ }^{11}$. Diabetes was reversed in these animal models, with accompanying normal glucose tolerance and partial endocrine pancreatic transdifferentiation of the liver resulting from the expression of several $\beta$-cell transcription factors. Indeed, it is the normal glucose tolerance displayed by these animals that sets our studies using the FFO technique apart from other regimes that have expressed insulin alone in the liver with no pancreatic transdifferentiation ${ }^{10,}{ }^{13}$. Attempts to induce pancreatic transdifferentiation using delivery of pancreatic transcription factors (notably $P d \times 1)$ have resulted in concomitant exocrine transdifferentiaiton and significant tissue damage $^{5,7}$. To apply this form of gene therapy to the clinical situation we must be able to show that primary human hepatocytes can undergo transduction with the insulin gene, and that these hepatocytes can undergo pancreatic transdifferentiation, as seen in livers of the animal models studied to date ${ }^{9-11}$. 
In the current study, we have utilised the FRG mouse model in which chimeric mousehuman livers can be readily established ${ }^{19,20}$. FRG mice have Tyrosinaemia type I $\left(\mathrm{Fah}^{-1-}\right)$ and lack both humoral and cell-mediated immunity as a consequence of Rag2 and $1 / 2 \mathrm{rg}^{-/-}$ deficiency $\left(\operatorname{Rag}^{-/} / / 1 / 2 \mathrm{rg}^{-/-}\right)$. The tyrosinaemic phenotype leads to the accumulation of hepatotoxic metabolites in host mouse hepatocytes, such that healthy human hepatocytes have an engraftment and growth advantage. We have used the FFO technique to deliver furin-cleavable human insulin (INS-FUR $)^{21}$, via a lentiviral vector $(H M D)^{22}$, to the livers of STZ-diabetic FRG mice. This has resulted in reversal of diabetes, restoration of glucose tolerance, and partial endocrine pancreatic transdifferentiation of both mouse and human hepatocytes in vivo. 


\section{Materials and Methods Vector production}

The HIV/ MSCV (HMD)/ INS-FUR lentiviral vector, which expresses both INS-FUR and enhanced green fluorescent protein (EGFP), was constructed as previously described ${ }^{9}$. The HMD lentiviral vector ${ }^{22}$ has a HIV/ murine stem cell virus hybrid long terminal repeat as the promoter and an internal ribosomal entry site, allowing bicistronic gene expression of both EGFP and INS-FUR. The vectors were produced by $\mathrm{Ca}_{3}\left(\mathrm{PO}_{4}\right)_{2}$ precipitation in 293T cells using conditioned medium, as described previously ${ }^{9}$. Culture medium was harvested $48 \mathrm{~h}$ after transfection and subjected to tangential flow filtration ${ }^{9}$, followed by pelleting of the vector $(75000 \mathrm{~g} / 2 \mathrm{~h})$. Virus titre was determined by transducing $293 \mathrm{~T}$ cells $\left(5 \mathrm{X} 10^{5}\right)$ with serially diluted vector stocks and quantifying numbers of EGFP-positive cells by flow cytometry, as previously described ${ }^{23}$. Viral replication-competency was also assessed by a p24 ELISA kit (CVPK-107, Cell Biolabs, San Diego, CA), following the manufacturer's instructions.

\section{Transduction of Liver Tissue}

Male and female, FRG mice were obtained from the Children's Hospital, Westmead where they had been bred following approval from the Westmead Hospital Animal Care and Ethics Committee (ACEC) (Approval No. C268). Maintenance and experimental manipulations were performed in accordance with the National Health and Medical Research Council of Australia principles of laboratory care and the relevant regulations of the Australian Research Council and were approved by the University of Technology Sydney (UTS) ACEC (Approval No. 2011-035A). Twenty-four hours prior to engraftment of human hepatocytes, 811 week old FRG mice received an intravenous injection of $6.4 \times 10^{9}$ plaque forming units of human urokinase adenoviral vector. Each animal received $1 \times 10^{6}$ human hepatocytes (Lonza, Basel, Switzerland) via intrasplenic injection. Cycles of (2-(2-nitro-4trifluoromethylbenzoyl)-1,3-cyclohexanedione (NTBC, Yechuris, Tualatin, OR, USA) were initiated $48 \mathrm{~h}$ after engraftment, as previously described ${ }^{19}$. NTBC cycling was continued until initiation of diabetes.

Liver repopulation was monitored by a human albumin ELISA kit and goat anti-human albumin HRP antibody (Bethyl Laboratories, Montgomery, TX, USA), as described ${ }^{19,24}$. It has been shown that the level of humanisation of the liver roughly correlates with human albumin levels in the blood, where a concentration of $1 \mathrm{mg} / \mathrm{ml}$ corresponds to $\sim 20 \%$ human hepatocytes ${ }^{24}$. Engrafted hepatocytes were allowed to expand for $\sim 150$ days before experimentation. Livers of animals used for further experimentation had approximately 50-$62 \%$ human hepatocytes, based on albumin measurements. Diabetes was induced by a 
single intraperitoneal injection of STZ $(170 \mathrm{mg} / \mathrm{kg})$. Mice that were assessed as diabetic (blood glucose $>12 \mathrm{mmol} / \mathrm{L}$ on 3 separate occasions) were used for experimentation. Animals were randomly allocated into groups of six and HMD/INS-FUR (INS-FUR carrying HMD vector) and HMD (empty vector) $\left(3.5 \times 10^{8}\right.$ transduction units [TDU]) were delivered to the liver via the portal circulation, by FFO, as previously described ${ }^{9,10}$.

\section{Functional Analyses}

After treatment, animals were monitored for body weight and blood glucose concentrations. IPGTTs (2g glucose/ $\mathrm{kg}$ after a $6 \mathrm{~h}$ fast) were carried out on the treated animals at 60 days after transduction together with diabetic and normal/nondiabetic controls $(n=6)$.

Non-fasting blood samples were collected from: HMD/INS-FUR-transduced FRG mice, nondiabetic FRG mice engrafted with human hepatocytes, and untransduced diabetic FRG mice engrafted with human hepatocytes. The levels of mouse and human C-peptide in the sera of mice were measured using a human C-peptide ELISA kit (E7HCP-20K) (Merck Millipore, Bayswater, VIC, Australia), and rat/mouse C-peptide ELISA kit (EZRMCP2-21K) (Merck Millipore). The insulin content of the liver and pancreas were measured following acidethanol extraction ${ }^{2}$. Levels of human and mouse insulin were measured using the EZ-14K (Merck Millipore) and the 90080 kit (Crystal Chem, Downer's Grove, IL), respectively.

To assess liver function, serum levels of alanine transaminase (ALT, Abcam, Cambridge, MA, ab105134) and aspartate aminotransferase (AST, Abcam 105135) were sampled at 2 and 10 days following the surgical delivery of INS-FUR and at sacrifice. As the model is quite fragile, it is not possible to take more frequent blood samples.

\section{Immunofluorescence Microscopic Analyses}

For immunofluorescence studies, serial frozen sections $(15 \mu \mathrm{m})$ of liver and pancreas were cut from all animals in the experimental groups. For triple staining of insulin, glucagon and somatostatin, the primary antibodies were mouse anti-human insulin (1:100, BioGenex, Fremont, CA), goat anti-glucagon (1:200 Santa Cruz Biotechnology, Dallas, TX), and goat anti-somatostatin (1:200, Santa Cruz). The secondary antibodies were anti-mouse IgG and anti-goat IgG (1:200, Vector Laboratories, Burlingame, CA). The fluorochromes were fluorescein avidin D, AMCA avidin D, and rhodamine avidin D (1:200, Vector Laboratories). For double staining of insulin and PDX1, the antibodies were mouse anti-insulin (1:100, BioGenex) and goat anti-PDX1 (1:100, Santa Cruz). The secondary antibodies used were anti-mouse IgG and anti-goat IgG (1:200, Vector Laboratories). The fluorochromes were fluorescein avidin D and rhodamine avidin D (1:200, Vector Laboratories). The staining 
procedure followed the fluorescein M.O.M kit (FMK-220, Vector Laboratories,). Between application of the primary antibodies against insulin and glucagon, glucagon and somatostatin and insulin and PDX1, the avidin/ biotin blocking kit (sp-200, Vector Laboratories) was used, following the manufacturer's instructions. Mounting medium containing DAPI (Vector Laboratories) was used to visualise nuclei.

For double staining of insulin and EGFP, insulin and human albumin, or FAH and human albumin, the liver sections were incubated for $1 \mathrm{~h}$ with antibodies against EGFP (1:100 Santa Cruz ), mouse anti-human insulin (1:100 BioGenex, CA and goat anti-human albumin (Abcam, Cambridge, MA), or mouse anti-human FAH (1:100, Sapphire Bioscience, Redfern, NSW, Australia) and goat anti-human albumin (Abcam), diluted 1:100 in 10\% v/v donkey serum at room temperature (RT). The secondary antibodies were then incubated for $1 \mathrm{~h}$ at RT with FITC-conjugated donkey anti-mouse IgG (for insulin or FAH), or rhodamine red conjugated donkey anti-goat IgG (Jackson ImmunoResearch, Westgrove, PA) for human albumin or EGFP, diluted $1: 100$ in $10 \% \mathrm{v} / \mathrm{v}$ donkey serum for $1 \mathrm{~h}$ at RT. Sections were mounted with Vectashield mounting medium with DAPI (Vector Laboratories). Ten sections were analysed from each animal for immunofluorescent studies. Digital images were acquired on a fluorescent microscope (Olympus BX60, Olympus Imaging, Macquarie Park, NSW, Australia) and captured with an Olympus camera. To count the number of double or triple positive-labelled cells on the acquired images, 6 random fields per section were ananlysed using the regions of interest analysis available in the Image Pro plus 6.2 software (Media Cybernetics, Inc, Rockville, MD). Data were analysed using Excel and a two-tailed Student's t-test was used to evaluate the results. Representative images are shown in the figures.

\section{Reverse transcriptase-PCR analyses}

For RT-PCR analysis, liver, pancreas and spleen were harvested at 60 days after vector infusion and snap-frozen in liquid nitrogen. Control pancreas was also obtained from nondiabetic FRG mice. Expression levels of transgenic insulin were examined in all tissues. Total RNA was extracted using Trizol (Invitrogen/ ThermoFisher Scientific, Waltman, MA), and samples were treated with DNase I (Invitrogen/ ThermoFisher Scientific) prior to RTPCR analyses. Expression of human and mouse insulin, other pancreatic hormones (glucagon, somatostatin and pancreatic polypeptide), $\beta$-cell transcription factors, and the exocrine marker, p48, were examined in liver and pancreas from untreated/nondiabetic FRG mice, and HMD/ INS-FUR-treated STZ-diabetic FRG mice (at 60 days, experimental endpoint). Primer concentrations and other PCR parameters were optimised for each primer 
set using DNA derived from normal control animals. All primers used in the study were species specific.

Real-time quantitative RT-PCR (RT-qPCR) using SYBR GreenER RT-qPCR Supermix (Invitrogen/ ThermoFisher Scientific) and a real-time detection system (Eppendorf Realplex2, Eppendorf South Pacific Pty Ltd, North Ryde, NSW, Australia) was used to determine the likelihood that both human and mouse cells contributed to the pancreatic transdifferentiation of the FRG livers by assessing the expression levels of a number of $\beta$ cell transcription factors and pancreatic hormones. RT-qPCR reactions contained either primers specific to the gene of interest, or the reference gene, $\beta$-actin. RT-PCR/ RT-qPCR primer sequences are available (Table S1). Melt curve analysis was performed to ascertain primer specificity. Pre-optimised TaqMan ${ }^{\circ}$ Gene expression Assays (Applied Biosystems/ ThermoFisher Scientific, Waltman, MA) were also used for the quantitation of the expression of mouse Pdx1, NeuroD1, Pax4, Ngn3, Nkx6.1, and MafA. TaqMan® gene expression assays identification numbers are available (Table S2). TaqMan assays for the reference gene, mouse $\beta$-actin, were also obtained and used for the quantitation of expression levels of the genes of interest. Taqman RT-qPCR assays were performed using the TaqMan® Fast Advance Master Mix (Applied Biosystems/ ThermoFisher Scientific), according to the manufacturer's protocol. The reactions were performed using the QuantStudio ${ }^{\mathrm{TM}} 6$ Flex Real $^{\circ}$ Time PCR System (ThermoFisher Scientific). Data was represented using the $2^{-\Delta \Delta t}$ method where $\Delta \Delta C T=\left(C_{t} \text {, Target }-C_{t} \text {, Reference }\right)_{\text {control tissue }}-\left(C_{t} \text {, Target }-C_{t} \text {, Reference }\right)_{\text {sample tissue }}$. The fold change in the target gene expression levels normalised to $\beta$-actin and measured relative to the expression levels in the control tissue, was calculated for each sample. The mean fold change \pm standard error of the mean (SEM) in the expression levels for each gene was then determined. Applied Biosystems QuantStudio ${ }^{\mathrm{TM}} 6$ \& 7 Flex Real-Time PCR System software was used to obtain the melting curves, the $\mathrm{Ct}$ values for the target and reference genes, the $\Delta \mathrm{Ct}$, the $\Delta \Delta \mathrm{Ct}$ values, as well as fold change differences in target gene expression levels in the different samples. Reactions were carried out in triplicate and experiments for each target gene were performed at least five times.

\section{Statistical Analysis}

Differences between groups in Fig. 3-2 were determined by a repeated measures analysis of variance. Log transformation of data was used where variances were heterogeneous. All other data was analysed using 2-tailed Student's-T-tests. Data were expressed as means \pm SEM. Differences were considered significant if $p<0.05$. 


\section{Results}

Engraftment and Repopulation of Human Hepatocytes in the Livers of FRG mice

Figure 1 shows a top view (Fig. 1A) and the underside (Fig. 1B) of a mouse liver 5 months after engraftment of human hepatocytes was commenced and prior to transduction with INSFUR. Significant engraftment of human hepatocytes (distinguished by the orange colouration) was observed throughout the entire liver. In particular, engraftment was pronounced on the underside of the liver lobes (Fig 1B). Hepatocyte engraftment was also monitored by measurement of blood human albumin concentration which increased throughout the engraftment period from $0.05 \pm 0.01 \mathrm{mg} / \mathrm{ml}$ at 50 days, $2.1 \pm 0.1 \mathrm{mg} / \mathrm{ml}$ at 100 days and $2.8 \pm 0.3 \mathrm{mg} / \mathrm{ml}$ at 150 days $(n=6)$, when transduction of the mouse livers took place.

In liver sections taken from areas observed to be heavily repopulated with human hepatocytes (Fig. 1), Serial frozen sections of livers were cut from the animals and the identity of the cells was confirmed by performing triple immunofluorescence staining of serial the sections with human-specific FAH and albumin, as well as DAPI staining of the nuclei (Fig 21). Fig. $2 A-1 A$ shows the expression of human $F A H$ and human albumin in a representative section from the liver of an engrafted FRG mouse treated with INS-FUR, together with DAPI nuclear staining. Analysis of images from areas heavily repopulated with human hepatocytes indicated that human $\mathrm{FAH}$ was detected in $89.6 \pm 9 \%$ of cells, human albumin in $92.9 \pm 10 \%$ of cells and $88.6 \pm 9.8 \%$ of cells stained positive for both human $\mathrm{FAH}$ and albumin. As expected, staining for human FAH and albumin in non-engrafted mice was negative (Fig. $2 \mathrm{~B} 1 \mathrm{~B}$ ). Figure $2 \mathrm{C}-1 \mathrm{C}$ represents a no antibody and no DAPI control of the mouse in Fig. $2 \mathrm{~A} 1 \mathrm{~A}$, where no staining is visible.

\section{Reversal of Diabetes in FRG mice}

Blood glucose levels of diabetic FRG mice decreased to normal levels within $24 \mathrm{~h}$ of transduction with the HMD/INS-FUR vector (Fig. $3 A \underline{2 A}$ ), and reversal of diabetes was maintained for 60 days (experimental endpoint). Diabetic FRG mice treated with HMD alone remained hyperglycaemic until day 2 (experimental endpoint). The body weights of diabetic mice treated with HMD/INS-FUR at day 0 were $23.6 \pm 0.7 \mathrm{~g}(\mathrm{n}=6)$, and this weight was maintained until day $60(24.2 \pm 1.3 \mathrm{~g})$. With the exception of the $30 \mathrm{~min}$ time point (when blood glucose concentrations of FRG mice treated with INS-FUR were significantly higher than those of control animals), there was no significant difference between the ability of diabetic FRG mice transduced with the HMD/INS-FUR vector and non-diabetic FRG mice to normalise blood glucose levels during intraperitoneal glucose tolerance tests (IPGTTs) (Fig. 3B $\underline{2 B}$ ). Diabetic FRG mice were unable to decrease blood glucose levels during IPGTTs 
(Fig. Зв2B). In INS-FUR treated FRG mice, non-fasting human C-peptide levels were $5.61 \pm 0.9 \mathrm{pmol} / \mathrm{L}$, and by comparison non-fasting mouse $\mathrm{C}$-peptide levels were significantly lower $(1.8 \pm 0.2 \mathrm{pmol} / \mathrm{L} ; \mathrm{p}<0.05)$. Human and mouse $\mathrm{C}$-peptide were not delectable in untreated diabetic animals. Human insulin storage was $2.4 \pm 0.1 \mathrm{nmol}$ in liver isolated from HMD/INS-FUR treated animals $(n=4)$ and mouse insulin was $0.6 \pm 0.1 \mathrm{nmol}$, as compared to $4.4 \pm 0.2 \mathrm{nmol}$ in normal mouse pancreas $(n=4)$. Mouse insulin was not detectable in acid ethanol extracts from the pancreas of HMD/INS-FUR-treated mice or diabetic controls.

There was a significant elevation of AST (526.4 $\pm 24.6 \mathrm{U} / \mathrm{l})$ and ALT levels $(330 \pm 7.4 \mathrm{U} / \mathrm{I}) 2$ days after surgical delivery of INS-FUR, compared to normal untreated animals (AST: 325.4 $\pm 2.5 \mathrm{U} / \mathrm{l}$; ALT: $259.8 \pm 5.4 \mathrm{U} / \mathrm{l})$. This elevation was transient with AST $(337.3 \pm 2.4 \mathrm{U} / \mathrm{l})$ and ALT $(270.8 \pm 5.9 \mathrm{U} / \mathrm{l})$ levels having returned to normal at 10 days after vector

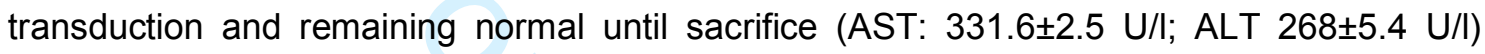
$(n=6)$.

Immunofluorescence staining for pancreatic hormones in liver tissue from FRG mice Serial sections of FRG mouse livers were stained for human albumin (Fig. 4A $\underline{3 A}$ ), human insulin (Fig. 4B $\underline{3 B}$ ) and with DAPI for nuclei (Fig. $4 \mathrm{C} \underline{3 \mathrm{C}}$ ). Analysis of merged images of combined human albumin and DAPI (Fig. 4D互), human albumin and insulin (Fig. 4E $\underline{E}$ ) and human albumin, insulin and DAPI (Fig. 4F $\underline{3 F}$ ) indicated that $41.4 \pm 13.3 \%$ of the cells were positive for human albumin, $34.7 \pm 6.8 \%$ were positive for insulin, and $19 \pm 3 \%$ were positive for both human albumin and insulin (Fig. 4F $\underline{3 F}$ ). The expression of EGFP $(32.6 \pm 2.4 \%)$ in the animals was not significantly different from insulin. We also examined FRG mouse livers for the expression of other pancreatic hormones which revealed extensive staining for insulin $(35.4 \pm 2.9 \%)$ with limited expression of glucagon $(1.0 \pm 0.2 \%)$ and somatostatin $(0.7 \pm 0.2 \%$ ) (Fig. $5 \mathrm{~A} \underline{4 \mathrm{~A}}$ ). Pancreatic hormones were not detected in normal engrafted FRG livers (Fig. $5 \mathrm{~B} \underline{4 \mathrm{~B}}$ ) or animals treated with empty vector (data not shown). Figure $5 \mathrm{C} \underline{4 \mathrm{C}}$ shows extensive insulin staining in the pancreas of normal (non-diabetic) FRG mice engrafted with human hepatocytes, however insulin-positive cells were rare, with $0.8 \pm 0.3 \%$ of the total cells staining positive for insulin in the pancreas of STZ-diabetic FRG mice treated with INS-FUR (Fig. 5D足), indicating that $\beta$-cell regeneration had not occurred. Staining for insulin together with PDX1, once again showed marked staining for insulin $(37.5 \pm 4.1 \%)$ and PDX1 $(33.5 \pm 3.5 \%)$, that were not significantly different from each other, (Fig. 5E $\underline{4 E}$ ). By comparison insulin and PDX1 were not detected in normal engrafted FRG livers (Fig. 5F $\underline{4 F}$ ). 


\section{Detection and quantification of expression levels of $\beta$-cell transcription factors and pancreatic hormones in FRG mouse livers transduced with INS-FUR.}

As expected from previous studies employing the FFO technique for the delivery of INS-FUR to animal livers ${ }^{9-11}$, INS-FUR expression was exclusively restricted to the livers of the FRG mice (Fig. 6AAㅡ). INS-FUR was not detected in livers of normal, FRG mice engrafted with human hepatocytes (Fig. 6B $\underline{5 B}$ ) or in animals transduced with empty vector (data not shown). In an attempt to further confirm that both human and mouse cells contributed to the pancreatic transdifferentiation of the FRG livers, the expression levels of a number of $\beta$-cell transcription factors and pancreatic hormones were determined by RT-PCR analysis. It can be seen from Figure 6B that the human $\beta$-cell transcription factors, Pdx1, Neurod1, Neurog3, Nkx2-2 and Pax4, were expressed in HMD/INS-FUR treated FRG livers, as were MAFA and MAFB, the insulin proconvertase, PC1, and synaptophysin. GLUT2 (S/ca2) and glucokinase were also expressed in transduced and normal liver and pancreas, as expected. The human pancreatic hormones, glucagon and somatostatin, were also expressed in HMD/INS-FUR transduced tissue, but not in normal liver. The pattern of expression of mouse transcription factors and hormones was similar to that observed for human transcription factors, with the exception that mouse Neurog3 was not detectable in FRG mouse pancreas or HMD/INSFUR-transduced liver, mouse Nkx6-1 was detected in HMD/INS-FUR treated FRG livers as were mouse insulin 1 and 2. Surprisingly, mouse glucagon and somatostatin were detected in both normal and transduced liver as was synaptophysin. The exocrine marker, p48, and pancreatic polypeptide (human and mouse) were not detected in any of the liver samples.

The expression levels of both human and mouse $\beta$-cell transcription factors and pancreatic hormones were examined by RT-qPCR and all expression results provided are relative to normal engrafted liver (Table S3). The results showed upregulation of several $\beta$-cell transcription factors (Fig. $6 \mathrm{G} \underline{\mathrm{CC}}$ ) and pancreatic hormones (Fig. $6 \square \underline{5 \mathrm{D}}$ ). Marked upregulation of human $P d x 1$, snaptophysin, insulin (as expected), glucagon and somatostatin and murine insulin 1 was observed (Fig. 6D $\underline{5 D}$ ). However, there was no discernible trend indicating higher levels of human transcription factors and pancreatic hormone expression when compared to the murine genes or vice versa. Whilst these RT-qPCR results do not definitely show the relative contributions of transdifferentiated human versus transdifferentiated murine liver cells to the reversal of diabetes and the normal glucose tolerance observed (Fig. 3B $\underline{2 B}$ ), the data suggest that there was contribution from both human and murine transdifferentiated hepatocytes. 


\section{Discussion}

In the current study, we have employed the chimeric FRG mouse model, which allows the engraftment and proliferation of human hepatocytes in mouse livers, to demonstrate the ability of INS-FUR (delivered by the lentiviral vector HMD and the FFO technique) to transduce human hepatocytes in vivo. Importantly, this resulted in the expression of human $\beta$-cell transcription factors and pancreatic hormones in the human hepatocytes in vivo. Whilst we have previously reported partial pancreatic transdifferentiation of rodent and porcine liver tissue using this methodology ${ }^{9-11}$, this is the first report of partial pancreatic transdifferentiation of primary human hepatocytes in vivo by the delivery of INS-FUR alone.

The engraftment success rate of human hepatocytes was high (50-62\%) without the requirement for serial transplantation of hepatocytes, as described in other studies ${ }^{20}$. This was likely related to the fact that engrafted hepatocytes were allowed to expand for 150 days prior to diabetes induction and experimentation. As seen in other studies ${ }^{19,20}$, serial sectioning and immunohistochemical analysis showed that in areas of liver heavily repopulated with human hepatocytes a high proportion of the cells (89\%) showed dual positivity for human $\mathrm{FAH}$ and human albumin confirming their human origin, as the murine hepatocytes in the FRG livers have an FAH deletion.

As we previously described in studies using the FFO technique to deliver the HMD/INS-FUR vector to diabetic animals ${ }^{9,10}$, blood glucose levels of STZ-diabetic FRG mice decreased to normal within the first day following transduction with INS-FUR, and remained not significantly different to normal animals for the period of experimentation (60 days). By comparison, animals treated with HMD alone remained hyperglycaemic, and were sacrificed 2 days after transduction. The immediate reduction in blood glucose concentrations may have been attributable to the expression of the INS-FUR transgene, with long term maintenance of normoglycaemia due to pancreatic transdifferentiation with insulin storage, as seen previously ${ }^{9}$. The reduction in blood glucose was not an effect of the surgical procedure or the lentiviral vector alone, as empty vector-treated animals remained hyperglycaemic. Definitive proof would require analysis of INS-FUR expression $24 \mathrm{~h}$ after gene transfer, which was not carried out in the current study. The body weights of the HMD/INS-FUR-treated animals remained relatively constant throughout the period of experimentation. Also, similar to our previous studies ${ }^{9-11}$, the glucose-responsiveness of INSFUR-treated animals (Fig. $3 \mathrm{~B} \underline{2 B}$ ) was not significantly different from the normal control animals. The one exception was the $30 \mathrm{~min}$ time point in the IPGTTs when the transduced animals had significantly higher blood glucose as compared to non-diabetic controls. This normal glucose tolerance is likely related to the storage of insulin in the mouse livers (as 
opposed to constitutive expression and unregulated secretion ${ }^{13}$ ), as the transduced hepatocytes had a reservoir of intracellular insulin, which allowed immediate responsiveness to increases in blood glucose concentrations, and insulin production was not reliant upon constitutive secretion ${ }^{13}$ or the delayed response from a glucose-responsive promoter to stimulate transcription, not translation or secretion ${ }^{4}$. Insulin storage was approximately half that of a normal mouse pancreas, which is within clinical limits for islet transplantation ${ }^{25}$. The presence of the other pancreatic hormones glucagon and somatostatin in close proximity to the cells that stained positive for insulin may have assisted with the normal response to glucose; however they were expressed at very low levels as assessed by immunohistochemical staining (Fig. $5 \mathrm{~A} \underline{\mathrm{AA}}$ ), which would limit the possibility of a significant biological effect. Future in-depth determination of pancreatic transdifferentiation could be ascertained by RNA-seq analysis as described ${ }^{26}$.

Due to the coexistence of both human and murine hepatocytes in the humanised mice and the significant storage of human and mouse insulin in transduced livers, it is a reasonable assumption that both populations of hepatocytes underwent a degree of pancreatic transdifferentiation and contributed to the amelioration of diabetes. We used RT-PCR and RT-qPCR to determine if human hepatocytes expressed $\beta$-cell transcription factors and pancreatic hormones, as observed in rodent and porcine cells following expression of HMD/INS-FUR ${ }^{9-11}$. The key human and mouse transcription factors, Pdx1, Neurod1 and $N k x .2$, were significantly upregulated in transduced livers. Extensive staining of PDX1 was also shown in INS-FUR-transduced livers (Fig. 5E $\underline{4 E}$ ), with no expression in untransduced livers (Fig. 5F4F). Human Pax4 was also significantly upregulated and human Ngn3 was detected, however mouse Pax4 and Ngn3 were not detected in the transduced liver and Ngn3 was absent from normal mouse pancreas. These results are not all together surprising as it is well documented that Pax 4 and $\mathrm{Ngn} 3$ are mainly expressed during the embryonic stage, during the differentiation of embryonic progenitor cells, and are rarely detected in the mature mouse pancreas ${ }^{27}$. MAFB was expressed in all murine samples, which corroborates our previous study using HMD/INS-FUR-transduced NOD mice, and other studies, which have observed its expression at the mRNA level in liver tissue ${ }^{10,28}$. Human and murine MAFA were only detected in transduced liver tissue, which may have been associated with the significant upregulation of mouse insulin 1 and 2 as MAFA is functionally linked to insulin gene transcription ${ }^{29}$. Similar to our previous studies using this technique pancreatic transdifferentiation was not complete, as human and mouse Pax6 and Pc2 were not detected. Fortunately, the exocrine marker, p48, was also not detected indicating exocrine differentiation was therefore prevented, and thus no destruction of transduced hepatocytes was seen, as observed in studies that induced transdifferentiation via the expression of 
$P d x 1^{5,7}$. Whilst human glucagon, somatostatin and synaptophysin were detected in transduced liver tissue alone, the corresponding murine factors were expressed, at the mRNA level, in normal engrafted liver. However, immunofluorescence staining of normal engrafted liver did not detect any protein expression of either glucagon or somatostatin, likely due to extremely low levels of expression of the proteins. RT-qPCR indicated that expression of human and mouse glucagon and synaptophysin and human somatostatin were significantly upregulated in the HMD/INS-FUR-treated livers, as compared to normal tissue. Whilst synaptophysin is known to modulate secretory pathways in pancreatic endocrine cells ${ }^{30}$, synaptophysin protein has been detected in the liver perisinusoidal stellate cells, in human and rat livers, and its expression levels increased in pathological conditions involving liver damage ${ }^{31}$. Thus, the expression of murine synaptophysin in the untransduced engrafted FRG livers may have resulted from tissue damage following hepatocyte engraftment, as may the expression of glucagon and somatostatin, which are normally expressed in the developing pancreas prior to insulin expression ${ }^{32}$. Indeed, the exposure of liver cells to toxins and cellular insults has been shown previously to induce liver-to-pancreas transdifferentiation $^{33}$. In the untransduced chimeric liver, the human hepatocytes were exposed to less damage than the mouse hepatocytes, which were FAH deficient and were further damaged by urokinase treatment, prior to human liver cell engraftment.

This is the first study to show clear transdifferentiation of human hepatocytes with storage of human insulin and the expression of human $\beta$-cell transcription factors and pancreatic hormones in an in vivo setting using a lentiviral system to deliver INS-FUR alone. However, the results of this study do not provide a definitive answer as to which transduced liver cell type, mouse or human, made the greatest contribution to the reversal of diabetes and normal glucose tolerance observed in the FRG mouse.

It has been established in our previous study utilising NOD mice ${ }^{10}$ and a study by Elsner et al using diabetic rats ${ }^{13}$, that the simple injection of a lentiviral vector containing a modified insulin transgene was sufficient to reduce daily blood glucose levels to near normal. However, no storage of insulin in the livers was detected and glucose tolerance was abnormal. As pancreas and liver come from the same endodermal origin, it has been previously documented that certain conditions such as insults to the cells or high glucose conditions can prime hepatocytes for pancreatic transdifferentiation ${ }^{33}$. It therefore seems likely that the insult provided by the FFO clamping technique and the delivery and expression of the INS-FUR transgene in the lentiviral vector collectively has led to the liverto-pancreas transdiffereniation in the current study. The transient rise seen in the liver enzymes AST and ALT following surgical delivery of the INS-FUR vector, which returned to normal within 10 days would seem to support this argument. Unpublished current work in our 
Acknowledgements: A.M.S and I.E.A initiated the concept of the study and A. M. S wrote the article. B.R. produced the vectors, performed the animal experiments, immunohistochemistry, RT-PCR, qRT-PCR analysis and data analysis. Q. L performed RTPCR and qRT-PCR analysis and data analysis. N.T.N. performed primer design and data analysis. Y. T, A. P. D. and R.M-W contributed to the animal experiments. D. G. and B. A. O'B contributed to experimental design and data analysis. F. T. designed the statistical analysis. All authors contributed to the interpretation of the data. The authors have no conflicts of interest.

The authors would like to thank Dr. Sharon Cunningham from the Children's Medical Research Institute, Westmead, Sydney for assistance in setting up the FRG model of hepatocyte engraftment at the University of Technology Sydney (UTS); Ms. Fiona Ryan and Ms. Lalit Overlunde (UTS) for assistance with the monitoring of the FRG model and Mr. R. Limburg for IT support. This study was supported by the Diabetes Australia Research Trust Millennium Award andthe Rebecca L. Cooper Medical Research Foundation. Q. L. and D. G. were supported by Australian Postgraduate Awards. 


\section{REFERENCES}

1. Eisenbarth GS. Type I diabetes mellitus: a chronic autoimmune disease. N Engl J Med 1986;4:1360-1368.

2. Simpson AM, Marshall GM, Tuch BE, et al. Gene Therapy of Diabetes: Glucosestimulated insulin secretion in a human hepatoma cell line. Gene Ther. 1997;4:2021215.

3. Tuch BE, Szymanska B, Yao M, et al. Function of a genetically modified human liver cell line that stores, processes and secretes insulin. Gene Ther. 2003;10:490-503.

4. Thule JM, Liu J, Phillips LS. Glucose regulated production of human insulin in rat hepatocytes. Gene Ther. 2000;7:205-214.

5. Ferber $\mathrm{S}$, Halkin $\mathrm{A}$, Cohen $\mathrm{H}$, et al. Pancreatic and duodenal homeobox gene 1 induces expression of insulin genes in liver and ameliorates streptozotocin-induced hyperglycaemia. Nature Med. 2000;6:568-572.

6. Ber I, Shternhall K, Perl S, et al. Functional, persistent, and extended liver to pancreas transdifferentiation. J. Biol. Chem. 2000;278:31950-31957.

7. Kojima H, Fujimiya M, Matsumara K, et al. NeuroD-betacellulin gene therapy induces islet neogenesis in the liver and reverses diabetes in mice. Nature Med. 2003;9:596603.

8. Sapir T, Shternhall K, Meivar-Levy I, et al. Cell-replacement therapy for diabetes: generating functional insulin-producing tissue from adult human liver cells. Proc. Natl. Acad. Sci. USA. 2005;102: 7964-7969.

9. Ren B, O'Brien B A, Swan MA, et al. Long-term correction of diabetes in rats after lentiviral hepatic insulin therapy. Diabetologia 2007;50:1910-1920.

10. Ren B, O'Brien BA, Byrne MR, et al. Long term reversal of diabetes in non obese diabetic mice by liver-directed gene therapy. J. Gene Med.2013;15:28-41.

11. Gerace D, Ren B, Hawthorne WJ, et al. Pancreatic transdifferentiation in porcine liver following lentiviral delivery of human furin-cleavable insulin. Trans. Proc. 2013;45: 1869-74.

12. Shternhall-Ron K, Quintana FJ, Perl S, et al. Ectopic PDX-1 expression in liver ameliorates type 1 diabetes. J. Autoimmunity. 2007;28:134-142.

13. Elsner M, Terbish T, Jorns A, et al. Reversal of diabetes through gene therapy of diabetic rats by hepatic insulin expression via lentiviral transduction. Mol. Ther. 2012;20: 918-926.

14. Permutt MA, Koranyi L, Keller K, Lacy PE, Scharp DW, Mueckler, M. Cloning and functional expression of a human pancreatic islet glucose-transporter. Proc. Natl. Acad. Sci. USA . 19889;86: 8688-8692.

15. Weinhouse, S. Regulation of glucokinase in the liver. In: Horecker BL, Stadtman ER, 
eds. Current topics in Cellular regulation. (New York, NY; San Francisco, CA; London, UK: Academic Press, 1976:1-50.

16. Tabiin MT, Tuch BE, Bai L, Han X, Simpson AM. Resistance of insulin-secreting hepatocytes to the toxicity of human autoimmune cytokines. Autoimmunity 2001;17:229-242.

17. Tabiin MT, White CP, Morahan G, Tuch BE. Insulin expressing hepatocytes not destroyed in transgenic NOD mice. J. Autoimmune Dis.2004;1: 3.

18. Lipes MA, Cooper EM, Skelly $R$, et al. Insulin-secreting non-islet cells are resistant to autoimmune destruction. Proc. Natl. Acad. Sci. USA. 1996;93:8595-8600.

19. Azuma H, Paulk N, Ranade A, et al. Robust expansion of human hepatocytes in Fah I-/Rag2 ${ }^{-/} / / \mathrm{Irg}^{-/}$mice. Nature Biotech. 2007;25:903-910.

20. Bissig K-D, Le T, Verma I M. Repopulation of adult and neonatal mice with human hepatocytes: a chimeric animal model. Proc. Natl. Acad. Sci. USA,2007;104:2050720511.

21. Groskreutz DJ, Sliwkowski M X, Gorman CM. Genetically engineered proinsulin constitutively processed and secreted as mature active insulin. J. Biol. Chem. 1994;269:6241-6245.

22. Choi, JK, Hoang N, Vilardi, AM, Conrad P, Emerson, SG, Gewirtz AM. Hybrid HIV/MSCV LTR enhances transgene expression of lentiviral vectors in human CD34+ hematopoetic cells. Stem Cells.2001;19:236-246.

23. Logan AC, Nightingale SJ, Haas DL, Cho GJ, Pepper, KA, Kohn D B. Factors influencing the titer and infectivity of lentiviral vectors. Hum. Gene Ther.2004;15: 976988.

24. Strom SC, Davila J, Grompe M. Chimeric mice with humanized liver: tools for the study of drug metabolism, excretion and toxicity. Methods Mol Biol. 2010;640: 491509.

25. Ryan EA, Lakey JR, Paty BW, et al. Successful islet transplantation. Continued insulin reverse provides long-term glycemic control. Diabetes. 2002;51:2148-2157.

26. Baron M, Veres A, Wolock SL, et al. A single-cell transcriptomic map of the human and mouse pancreas reverses inter- and intra-cell population structure. Cell Syst. 2016;3: 346-360.

27. Gu G, Dubauskaite J, Melton DA. Direct evidence for the pancreatic lineage: NGN3+ cells are islet progenitors and are distinct from duct progenitors. Development. 2002;129:2447-2457.

28. Sakai M, Imaki J, Yoshida K, et al. Rat maf related genes: specific expression in chondrocytes, lens and spinal cord. Oncogene. 2009;14:7145-750. 
29. Zhao L, Guo M, Matsuoka T, et al. The islet $\beta$ cell-enriched MafA activator is a key regulator of insulin gene transcription. J. Biol. Chem. 2005;280:11867-11894.

30. Redecker P, Jörns A, Jahn R, Grube D. Synaptophysin immunoreactivity in the mammalian endocrine pancreas. Cell Tissue Res. 1991;264:461-7.

31. Cassiman D, Van Pelt J, De Vos R, et al. Synaptophysin: a novel marker for human and rat hepatic stellate cells. Amer. J. Path.1999;155:1831-1839.

32. Park I-S, Bendayan M. Development of the endocrine cells in the rat pancreatic and bile duct system. Histochem. J. 1993;25:807-820.

33. Shanmukhappa K, Mourya R, Sabla GE, Degen JL, Bezerra JA. Hepatic to pancreatic switch defines a role for hemostatic factors in cellular plasticity in mice. Proc. Natl. Acad. Sci. USA.2005;102:10182-10187.

34. Rothe M, Modlich $U$, Scambach A. Biosafety challenges for the use of lentiviral vectors in gene therapy. Curr Gene ther. 2013;13: 453-68.

\section{List of Table Legends}

Table S1: RT-PCR Primers

Table S2: TaqMan assay identification of murine genes

Table S3; Results of RT-qPCR analysis of human and mouse $\beta$-cell transcription factors and pancreatic hormones in INS-FUR-treated FRG mouse liver tissue compared to untransduced FRG mouse liver. 


\section{Figure Legends}

Figure 1 Engraftment and repopulation of human hepatocytes in adult FRG mice. targo areas of human hopatocytes (orango) aro shown in all liver lobes (A) top view of the liver and (B) underside of the lobes of the liver in a FRG mouse 5 months after commencement of the engraftment procedure and prior to the delivery of the HMDIINS-FUR vector. Selected areas of human hepatocyte repopulation are indicated with arrows.

Figure 21 Expression of human FAH and human albumin in liver tissue from FRG mice treated with INS-FUR. Representative photomicrographs of immunofluorescence staining for human FAH, human albumin and DAPI stained nuclei, together with a merged image, in (A) liver tissue from an FRG mouse 60 days after treatment with INS-FUR; (B) liver tissue from a nonengrafted, non-diabetic FRG mouse of the same age and (C) a no antibody, no DAPI control of liver tissue from the mouse in A. Scale bar $=40 \mu \mathrm{m}$.

Figure $3 \underline{2}$ Expression of INS-FUR ameliorated STZ-induced diabetes in FRG mice. (A) Blood glucose concentrations of non-diabetic engrafted FRG mice and diabetic engrafted mice treated with HMD/INS-FUR and HMD alone. (B) Blood glucose levels following IPGTTs of nondiabetic engrafted FRG mice, diabetic mice treated with HMD/INS-FUR, and diabetic controls 60 days after vector infusion ( $n=6$; means \pm SEMs).

Figure $4 \underline{3}$ Expression of human albumin and insulin in liver tissue from FRG mice treated with INS-FUR. Representative photomicrographs of immunofluorescence staining for (A) albumin, (B) insulin and (C) DAPI nuclei staining in liver tissue from an FRG mouse 60 days after treatment with INSFUR. (D) merged image of $A$ and $C$; (E) merged image of $A$ and $B$; (F) is a merged image of $A, B$, and C. Scale bar $=40 \mu \mathrm{m}$.

Figure 54 Expression of pancreatic hormones and PDX1 following reversal of STZdiabetes after treatment with INS-FUR. Representative photomicrographs of triple immunofluorescence staining for insulin (INS), somatostatin (SST), glucagon (GLUC) and a merged image in: (A) liver from a diabetic FRG mouse treated with HMD/INS-FUR 60 days previously; (B) liver from an untreated FRG mouse; (C) pancreas from an untreated non-diabetic FRG mouse and (D) pancreas from a diabetic FRG mouse treated with HMD/INSFUR 60 days previously. (E) and (F) are representative photomicrographs of 
immunofluorescence staining for insulin (INS), PDX1, DAPI stained nuclei and a merged image in: liver from a diabetic FRG mouse treated with HMD/INS-FUR 60 days previously and liver from an untreated FRG mouse respectively. Scale bar $=40 \mu \mathrm{m}$.

Figure $6 \underline{5} \quad$ Expression of $\beta$-cell transcription factors and pancreatic hormones in FRG mice 60 days after transduction with HMD/INS-FUR. (A) RT-PCR analyses of tissues for expression of INS-FUR and $\beta$-actin (Actb) in animals transduced with HMD/INS-FUR : spleen (lane 1), pancreas (lane 2), and liver (lane 3) (B) RT-PCR analysis for human and mouse $\beta$-cell transcription factors (Pdx1, Neurod1, Neurog3, Nkx2-2, Nkx6-1, Pax 4, Pax 6, MAFA, MAFB), insulin proconvertase 1 and 2 (Pc1 and Pc2), GLUT 2 (S/c2a2), and glucokinase (Gck); synaptophysin (Synap), exocrine marker p48; the pancreatic endocrine hormones: glucagon (Gcg), somatostatin (Sst), mouse insulin 1 and 2 (M.Ins1 and M.Ins2), human insulin (H.Ins), pancreatic polypeptide (Ppy) and Actb in normal liver (lane 1), liver transduced with HMD/INS-FUR (FFO) (lane 2) and either human islets or normal mouse pancreas (lane 3). Results of RT-qPCR analysis of human and mouse $\beta$-cell transcription factors (C) and pancreatic hormones (D) that were significantly upregulated in INS-FUR-treated FRG mouse liver tissue compared to normal liver. Five replicates of each treatment, each consisting of at least 3 methodological replicates were used. Expression data for each gene of interest are presented as the average and SEM of data obtained for each gene, compared to untransduced FRG liver. 
FAH

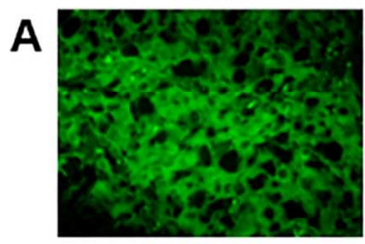

B

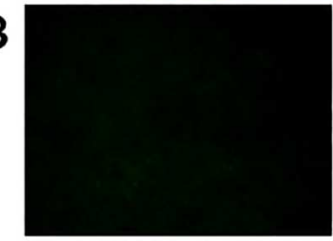

C

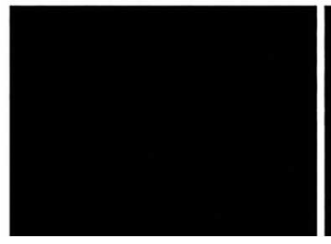

ALBUMIN
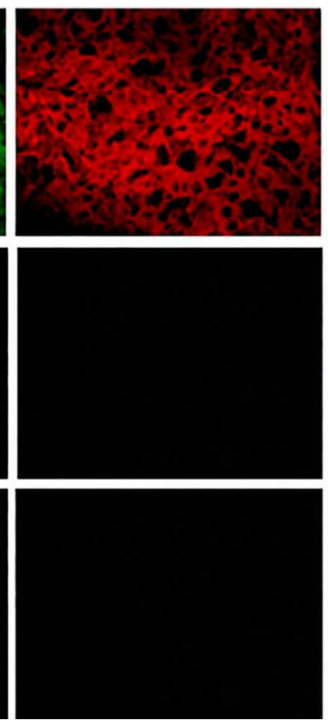

NUCLEI
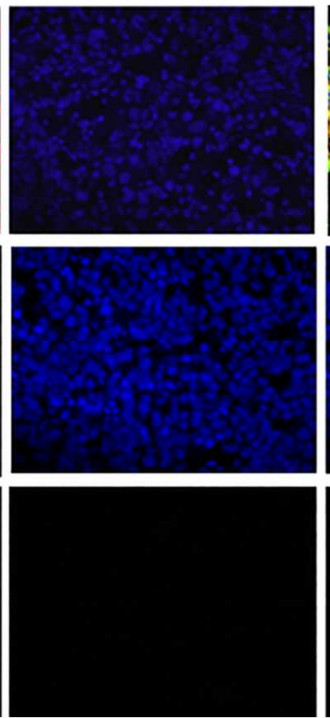

MERGED
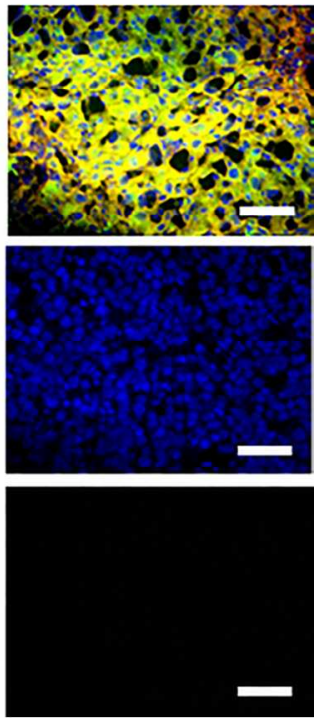

Figure 1 Expression of human FAH and human albumin in liver tissue from FRG mice treated with INS-FUR. Representative photomicrographs of immunofluorescence staining for human FAH, human albumin and DAPI stained nuclei, together with a merged image, in (A) liver tissue from an FRG mouse 60 days after treatment with INS-FUR; (B) liver tissue from a non-engrafted, non-diabetic FRG mouse of the same age and (C) a no antibody, no DAPI control of liver tissue from the mouse in A. Scale bar= $40 \mu \mathrm{m}$.

$$
98 \times 56 \mathrm{~mm}(300 \times 300 \mathrm{DPI})
$$



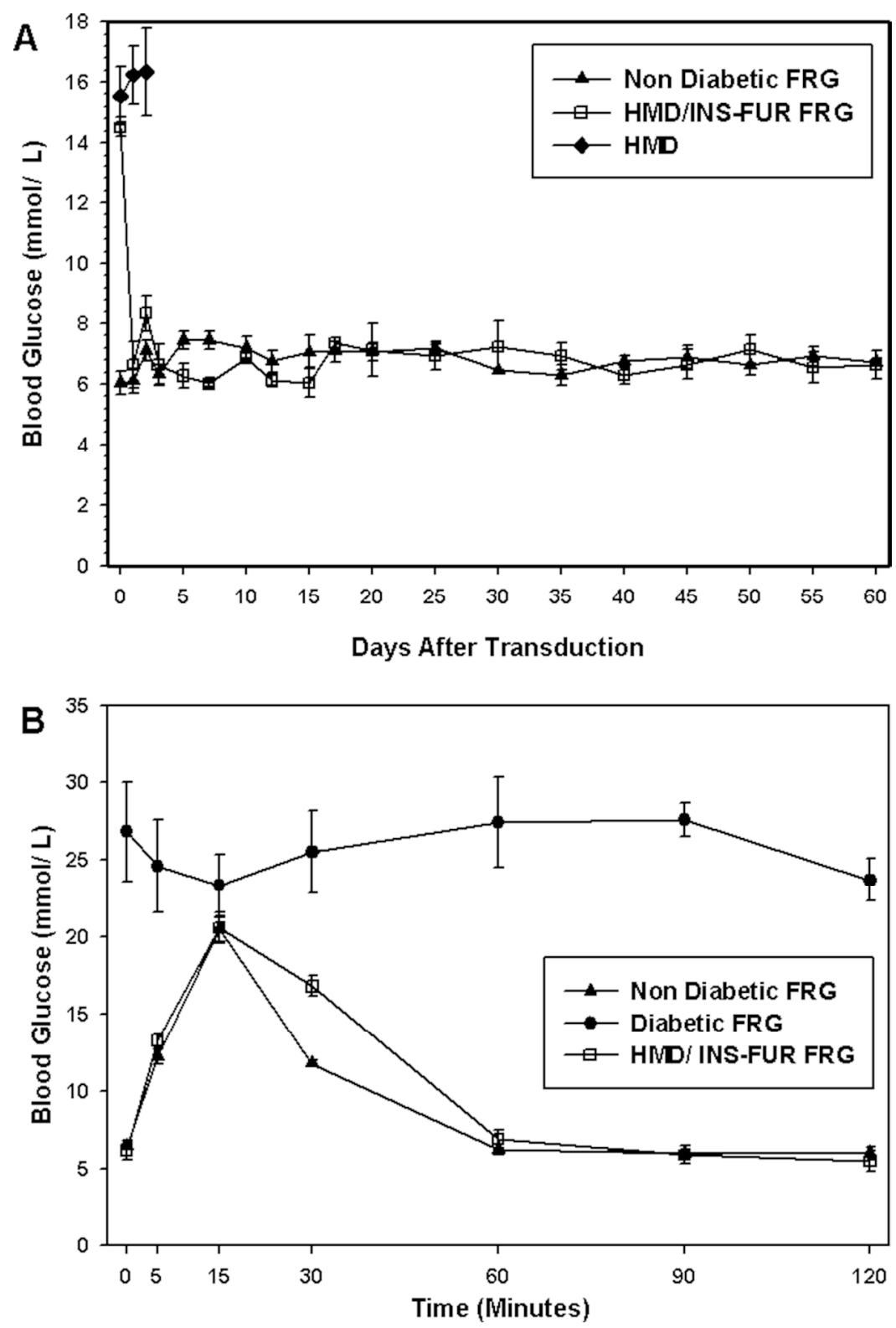

Figure 2 Expression of INS-FUR ameliorated STZ-induced diabetes in FRG mice. (A) Blood glucose concentrations of non-diabetic engrafted FRG mice and diabetic engrafted mice treated with HMD/INS-FUR and HMD alone. (B) Blood glucose levels following IPGTTs of nondiabetic engrafted FRG mice, diabetic mice treated with HMD/INS-FUR, and diabetic controls 60 days after vector infusion ( $n=6$; means \pm SEMs).

$132 \times 197 \mathrm{~mm}(600 \times 600 \mathrm{DPI})$ 

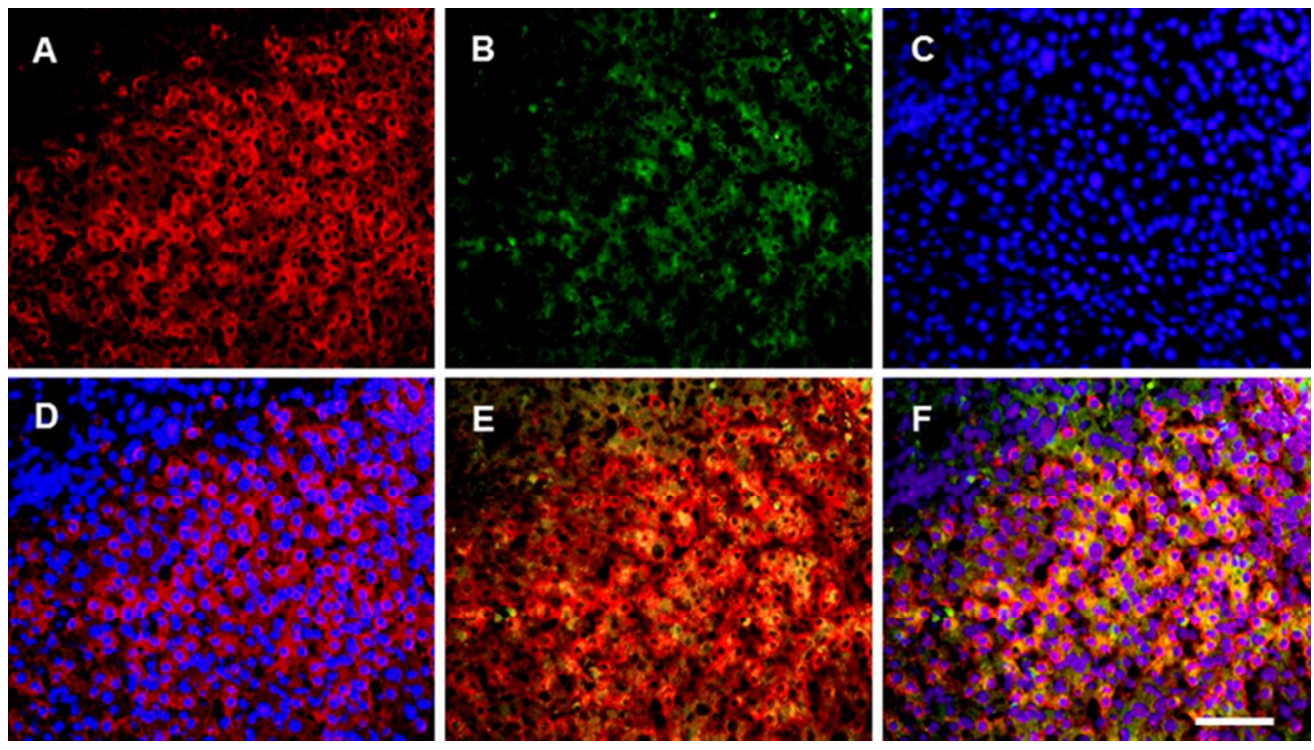

Figure 3 Expression of human albumin and insulin in liver tissue from FRG mice treated with INS-FUR. Representative photomicrographs of immunofluorescence staining for (A) albumin, (B) insulin and (C) DAPI nuclei staining in liver tissue from an FRG mouse 60 days after treatment with INS-FUR. (D) merged image of $A$ and $C ;(E)$ merged image of $A$ and $B ;(F)$ is a merged image of $A, B$, and $C$. Scale bar $=40 \mu \mathrm{m}$.

$$
67 \times 38 \mathrm{~mm}(300 \times 300 \mathrm{DPI})
$$



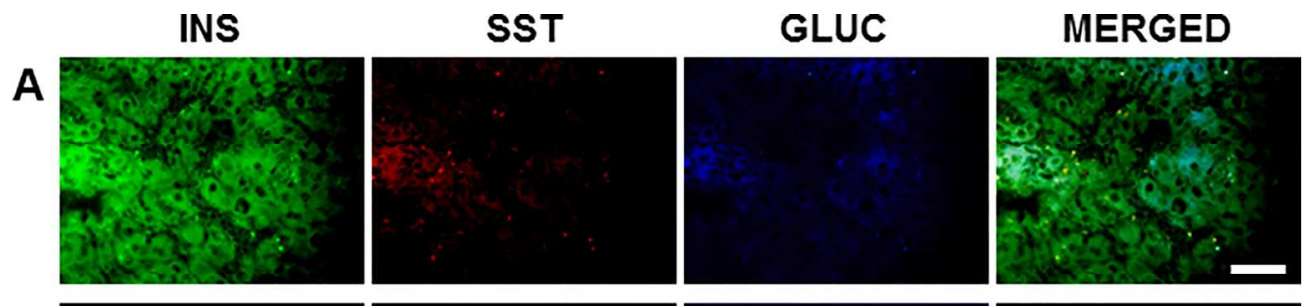

B
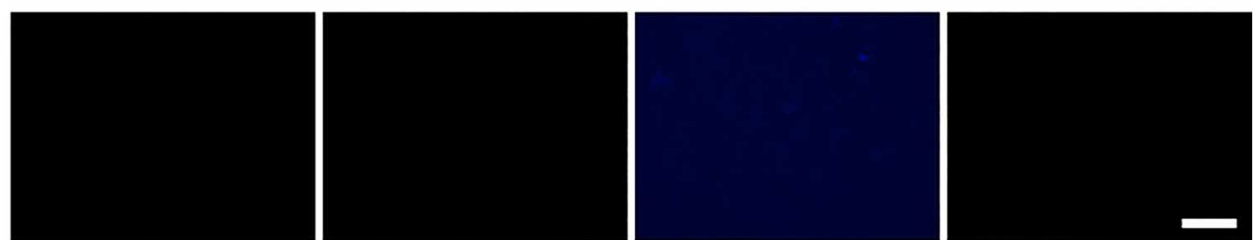

C
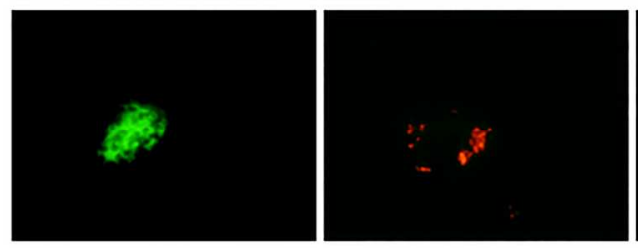

D
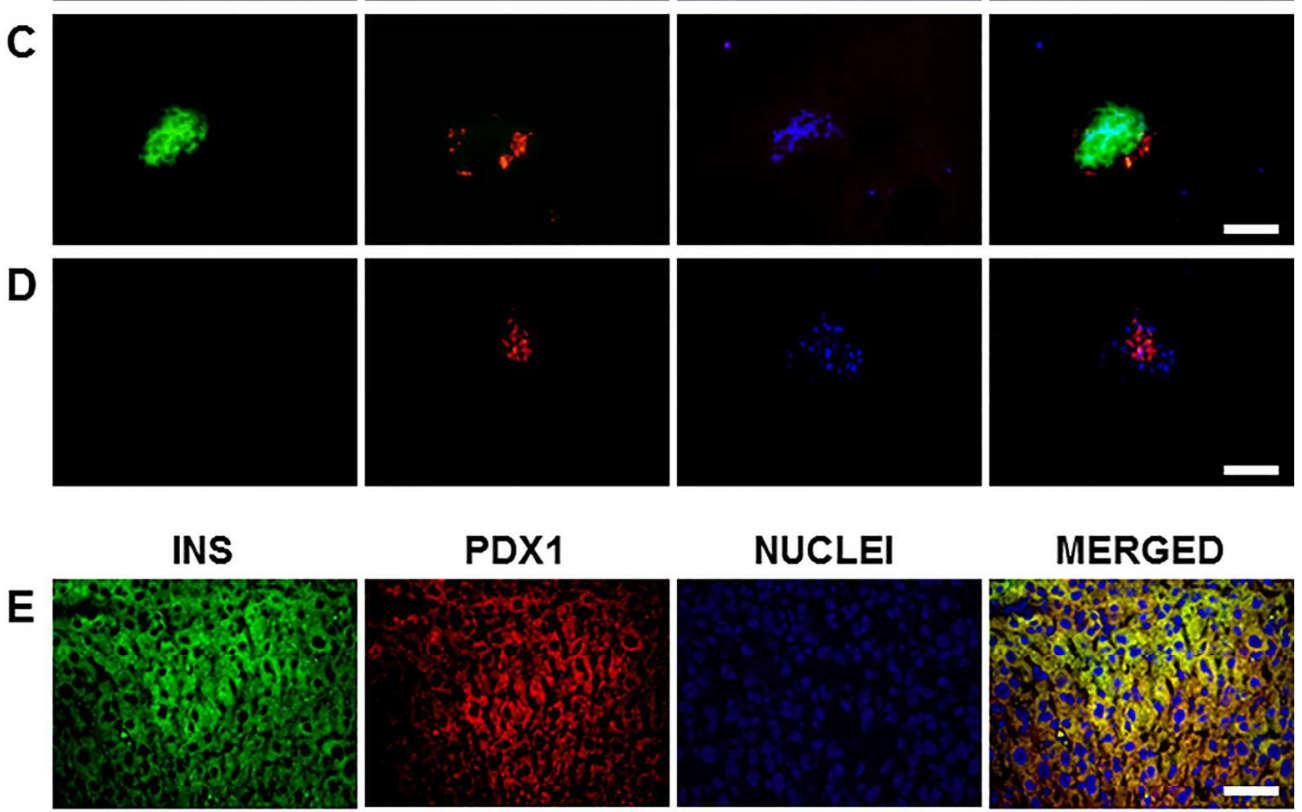

NUCLEI

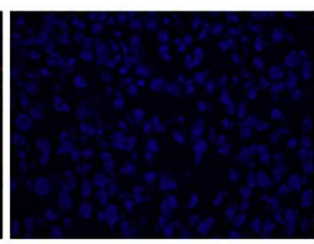

MERGED

F
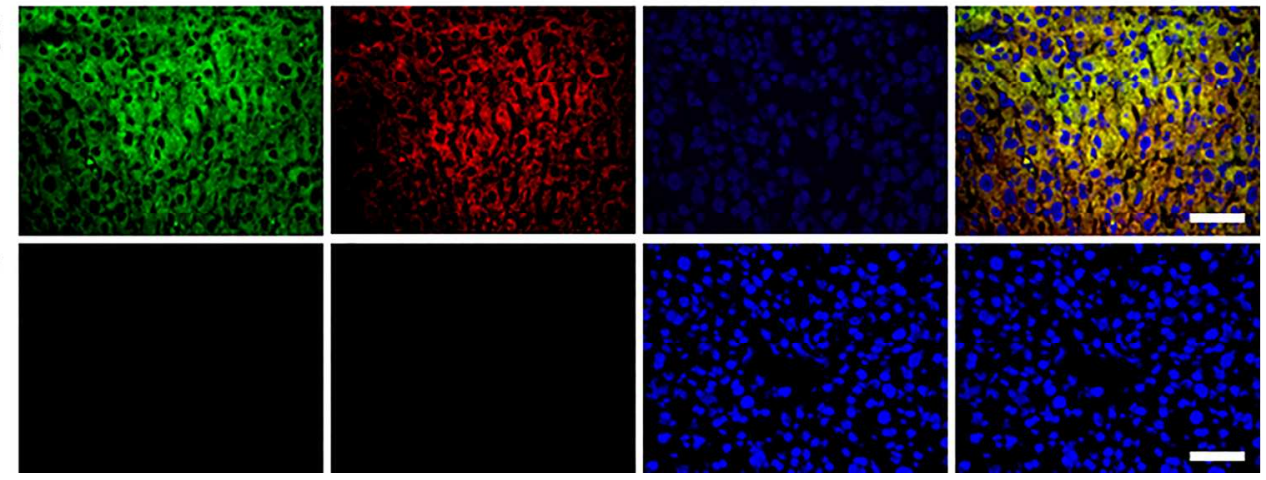

Figure 4 Expression of pancreatic hormones and PDX1 following reversal of STZ-diabetes after treatment with INS-FUR. Representative photomicrographs of triple immunofluorescence staining for insulin (INS), somatostatin (SST), glucagon (GLUC) and a merged image in: (A) liver from a diabetic FRG mouse treated with HMD/INS-FUR 60 days previously; (B) liver from an untreated FRG mouse; (C) pancreas from an untreated non-diabetic FRG mouse and (D) pancreas from a diabetic FRG mouse treated with HMD/INS-FUR 60 days previously. (E) and (F) are representative photomicrographs of immunofluorescence staining for insulin (INS), PDX1, DAPI stained nuclei and a merged image in: liver from a diabetic FRG mouse treated with HMD/INS-FUR 60 days previously and liver from an untreated FRG mouse respectively. Scale bar $=40$ $\mu \mathrm{m}$. 


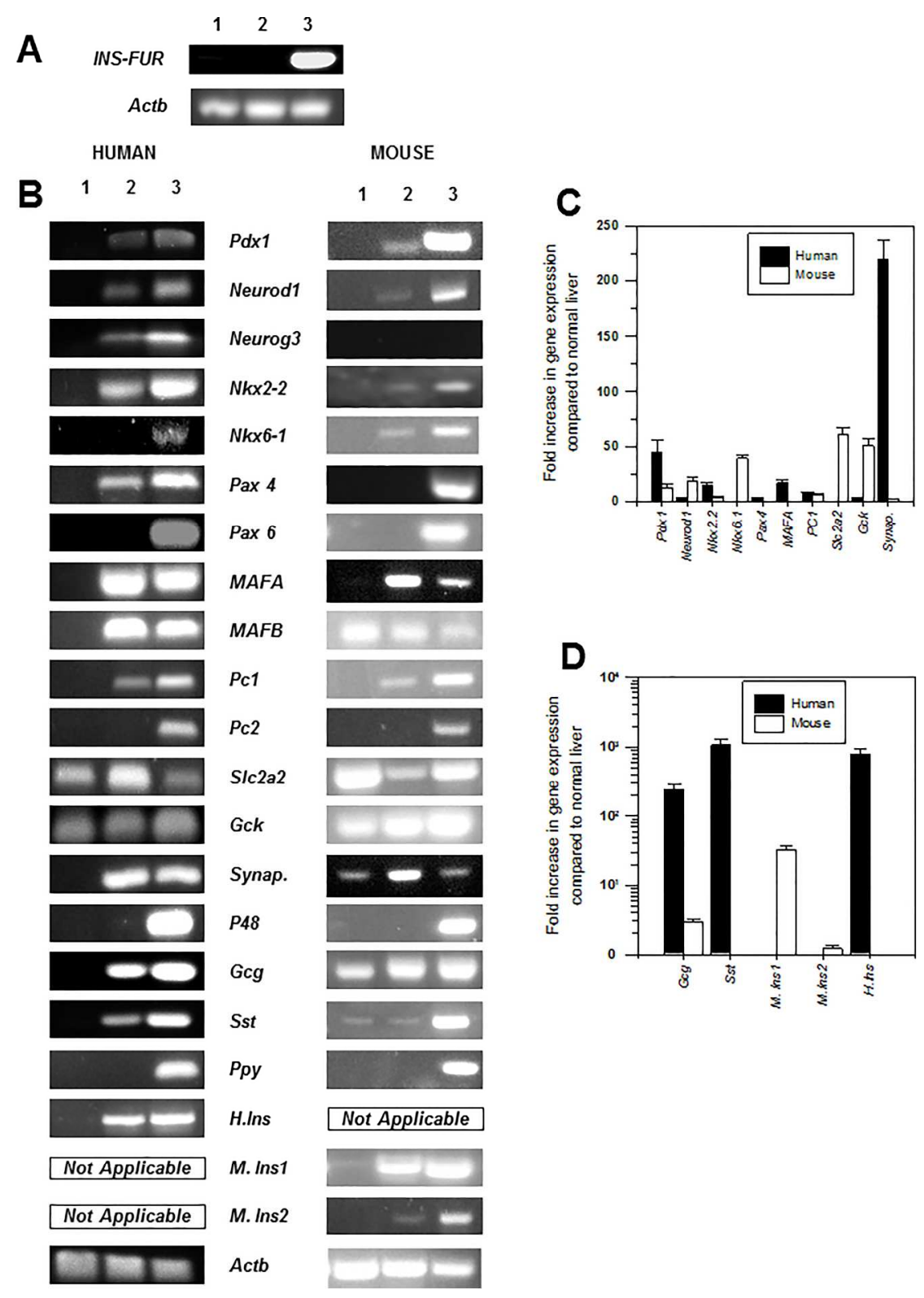

Figure 5 Expression of $\beta$-cell transcription factors and pancreatic hormones in FRG mice 60 days after transduction with HMD/INS-FUR. (A) RT-PCR analyses of tissues for expression of INS-FUR and $\beta$-actin (Actb) in animals transduced with HMD/INS-FUR : spleen (lane 1), pancreas (lane 2), and liver (lane 3) (B) RT-PCR analysis for human and mouse $\beta$-cell transcription factors (Pdx1, Neurod1, Neurog3, Nkx2-2, Nkx6-

1, Pax 4, Pax 6, MAFA, MAFB), insulin proconvertase 1 and 2 (Pc1 and Pc2), GLUT 2 (SIc2a2), and glucokinase (Gck); synaptophysin (Synap), exocrine marker p48; the pancreatic endocrine hormones: glucagon (Gcg), somatostatin (Sst), mouse insulin 1 and 2 (M.Ins1 and M.Ins2), human insulin (H.Ins), pancreatic polypeptide (Ppy) and Actb in normal liver (lane 1), liver transduced with HMD/INS-FUR (FFO) (lane 2) and either human islets or normal mouse pancreas (lane 3). Results of RT-qPCR analysis of human and mouse $\beta$-cell transcription factors (C) and pancreatic hormones (D) that were significantly upregulated in INS-FUR-treated FRG mouse liver tissue compared to normal liver. Five replicates of each treatment, each consisting of at least 3 methodological replicates were used. Expression data for each gene of interest are presented as the average and SEM of data obtained for each gene, compared to untransduced FRG liver. 
Table S1: RT-PCR Primers

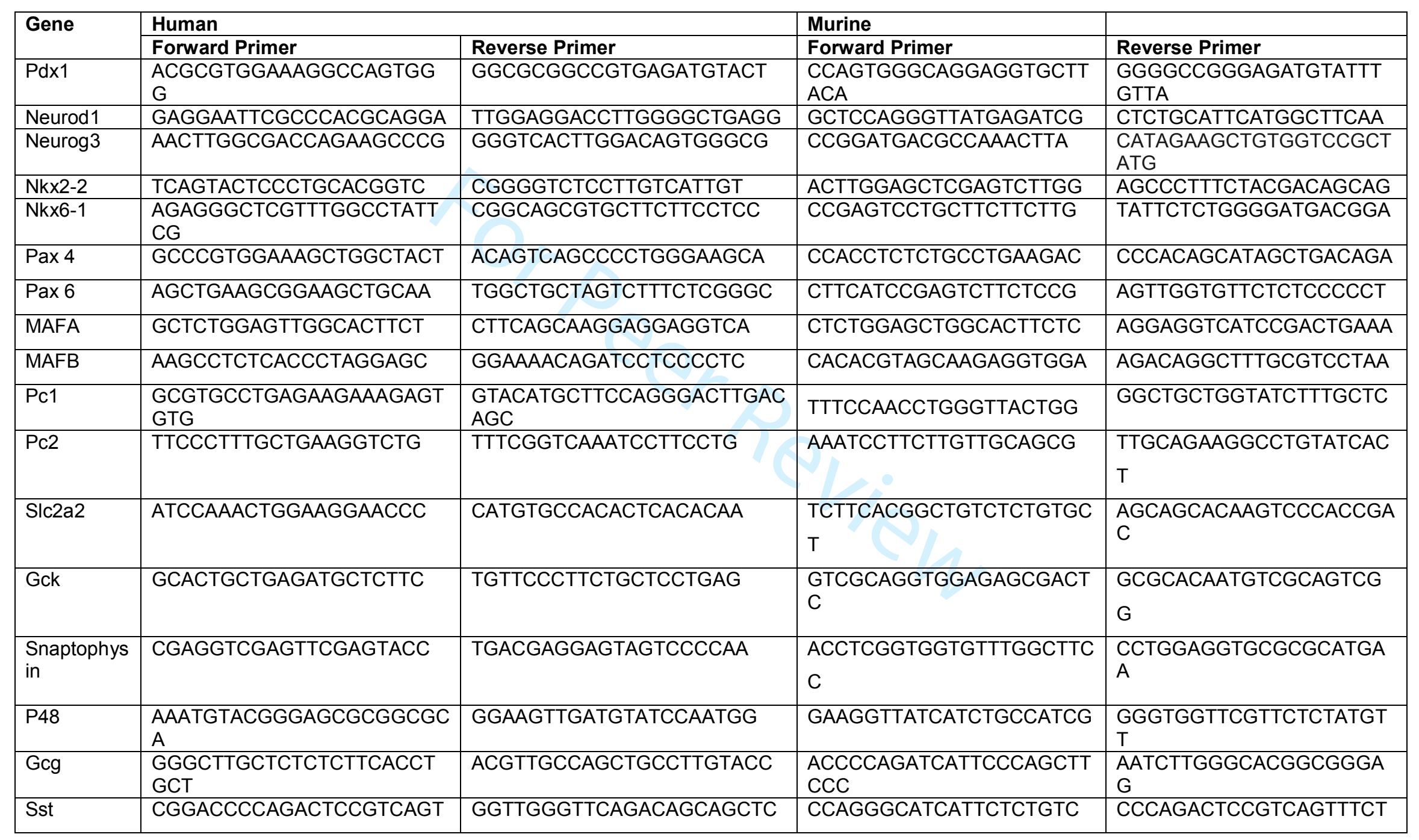




\begin{tabular}{|c|c|c|c|c|}
\hline Ppy & $\begin{array}{l}\text { TCGCTTGGTCTAGTGCCCATTT } \\
\text { AC }\end{array}$ & GCACCCAGCAGTGGCTGTAGT & GCATAGTCGCCTGGGTACAT & $\begin{array}{l}\text { CCAACACTCACTAGCTCAGC } \\
\text { A }\end{array}$ \\
\hline INS-FUR & CTTACCATGGCCCTGTGGAT & TAGAAGAAGCCTCGTTCCCC & & \\
\hline $\begin{array}{l}\text { Mouse Ins } \\
2\end{array}$ & $\mathrm{~N} / \mathrm{A}$ & $\mathrm{N} / \mathrm{A}$ & GAGTCCCACCCCACCCAG & TCCACTTCACGGCGGGACA \\
\hline Actb & $\begin{array}{l}\text { CTGAGGCACTCTTCCAGCCTT } \\
\text { CCTT }\end{array}$ & $\begin{array}{l}\text { AGGTCTTTGCGGATGTCCACGT } \\
\text { CA }\end{array}$ & ATGGAGGGGAATACAGCCC & TTCTTTGCAGCTCCTTCGTT \\
\hline
\end{tabular}


Table S2: TaqMan $®$ assay for quantitation of murine gene expression

\begin{tabular}{|l|l|}
\hline Gene & TaqMan Assay Identification No. \\
\hline Murine Actb & Mm02619580_g1 \\
\hline Murine Mafa & Mm00845206_s1 \\
\hline Murine Pax4 & Mm01159036_m1 \\
\hline Murine Pdx1 & Mm00435565_m1 \\
\hline Murine NeuroD1 & Mm01946604_s1 \\
\hline Murine Ngn3 & Mm01173349_g1 \\
\hline Murine Nkx6.1 & Mm00454961_m1 \\
\hline
\end{tabular}




\section{Table S3}

Results of RT-qPCR analysis of human and mouse $\beta$-cell transcription factors and pancreatic hormones in INS-FUR-treated FRG mouse liver tissue compared to normal liver.

\begin{tabular}{|l|c|c|}
\hline \multicolumn{2}{|c|}{ Fold increase in gene expression compared to normal liver } \\
\hline Pdx1 & Human & Mouse \\
\hline Neurod1 & $44.7 \pm 10.6^{*}$ & $12.34 \pm 3.4^{*}$ \\
\hline Neurog3 & $2.4 \pm 0.6^{*}$ & $18.5 \pm 3.3^{*}$ \\
\hline Nkx2-2 & $3.6 \pm 0.7$ & Not detected \\
\hline Nkx6-1 & $14.7 \pm 2.3^{*}$ & $4.2 \pm 0.6^{*}$ \\
\hline Pax4 & Not detected & $39.16 \pm 2.6^{*}$ \\
\hline MAFA & $3.4 \pm 0.5^{*}$ & Not detected \\
\hline MAFB & $17.1 \pm 2.2^{*}$ & $85.8 \pm 37.9$ \\
\hline PC1 & $196.1 \pm 19.8$ & $5.3 \pm 4.6$ \\
\hline Slc2a2 & $8.6 \pm 0.3^{*}$ & $6.6 \pm 0.4^{*}$ \\
\hline Gck & No change & $61.2 \pm 5.6^{*}$ \\
\hline Synaptophysin & $3.2 \pm 0.3^{*}$ & $50.8 \pm 6.9^{*}$ \\
\hline Glucagon & $219.5 \pm 18.5^{*}$ & $2.4 \pm 0.3^{*}$ \\
\hline Somatostatin & $2460.3 \pm 422.3^{*}$ & $29.2 \pm 2.6^{*}$ \\
\hline Mouse insulin 1 & $10680.5 \pm 2324.9^{*}$ & $0.1 \pm 0.0$ \\
\hline Mouse insulin 2 & $\mathrm{N} / \mathrm{A}$ & $322.4 \pm 54.1^{*}$ \\
\hline Human insulin & $\mathrm{N} / \mathrm{A}$ & $12.2 \pm 1.2^{*}$ \\
\hline Five replicates & $\mathrm{N} / \mathrm{A}$ \\
\hline
\end{tabular}

Five replicates of each treatment, each consisting of at least 3 methodological replicates were used. Expression data for each gene of interest are presented as the average and SEM of data obtained for each gene, compared to untransduced FRG liver. . Asterisks indicate a statistically significant fold change in expression compared to normal engrafted liver at alpha $=0.05$. 